\title{
Modelling the Entrepreneurial Space-Economy: an overview
}

\author{
Peter Nijkamp \\ Department of Regional Economics \\ Free University Amsterdam
}

and

Leo van Wissen

Urban and Regional Studies Institute URSI, University Groningen / Royal Netherlands

Academy of Sciences/NIDI, The Hague

Correspondence: 1.j.g.van.wissen@frw.rug.nl

Pn144lvw

\begin{abstract}
The aim of this paper is to review recent contributions to the study of entrepreneurship and firm dynamics from a methodological and firm demographic perspective. Understanding the contemporary changes in business life requires a thorough understanding of structural changes in entrepreneurial behaviour and firm dynamics, both in space and in time. The spatial and temporal aspects of business life have in recent years received much attention, and a review is given here. The framework concept of the 'firm life course' is proposed in this article to integrate both dimensions. The firm life course represents the way firms organize their life path over time in sequences of critical events, decisions, and periods. The dimensions of time and space appear to be highly connected in business life. Not only is firm mobility increasing, but also are entrepreneurs increasingly acting as networkers. The emergence of virtual and dynamic networks of entrepreneurs calls for new methods of research of dealing with them. This article maps out some of the modern research trends in this domain.
\end{abstract}

Paper Peter Nijkamp - Leovanwissen version 10 June 


\section{Entrepreneurship in a Modern Economy}

Industrial dynamics is decisive for the evolution of cities and regions. But such evolutionary processes are not the result of autonomous or given factors, but are instigated by innovative behaviour and modern entrepreneurship. Innovation and entrepreneurship imply the design, production and successful exploitation of new ideas, knowledge, technologies, products, procedures, processes, regulations or organizational modes. Smart competitive strategies are a sine qua non for a successful city or region (see Suarez-Villa 1989, Acs 2002, van Oort 2004).

Clearly, entrepreneurship is not just a feature of our age. In the nineteenth century, in the period of the Industrial Revolution, we have even seen an avalanche of innovations in the context of a new entrepreneurial spirit. Since then, there have apparently been waves of new entrepreneurship and innovations. In the early years of the twenty-first century, the centrality of entrepreneurship in economic development is unquestioned. New firms and new industries continue to fill gaps in the market left by established firms (Norton 2001). New gaps continue to appear, as societies demand new services as well as old services in new forms and at extended times. The internet and related information and communications technologies (ICTs) are central to the changes that are taking place. Entrepreneurs, particularly knowledge-based and technology-based entrepreneurs, find the agglomeration advantages of large cities attractive and, therefore, reinforce those advantages. The effects of these technologies are not unidirectional, relaxing or completely eliminating the constraints of distance on economic and social activities (see also Oakey 1996, Boekema et al. 2000, Marsili 2001, Peneder 2001, van Oort 2004). In the modern network age, we observe fascinating strategies of entrepreneurs seeking to enter or survive in a competitive market. Cities offer interesting and promising breeding places for innovative entrepreneurial activities, either by means of extensive ICT usage or by exploiting the potential of traditional informal networks. In both cases, however, we witness a reinforcement of urban functions, and hence the conclusion is warranted that cities are the sites par excellence for entrepreneurial innovation in a modern network era. Consequently, we witness at present a revival of studies on entrepreneurship.

At least, three strands of literature can be observed in modern entrepreneurship. A first strand addresses the innovative potential of entrepreneurship in the SME sector. Another field of interest is concerned with regional and urban network systems as seedbed conditions for the innovation potential of firms. And a final major focal point relates to the synergy of private and public policy. In all these strands of interest we observe a great deal of interest in the opportunities offered by the ICT sector, as well as by learning strategies which may provide competitive advantages in a technological, institutional or organizational respect. The emergence of virtual organizations in a complex dynamic setting characterized by flexible specialization, evolutionary principles and governance trust are illustrative for these recent phenomena.

The aim of the present paper is to review recent entrepreneurial studies from a methodological perspective on firm demographics. The emphasis will be laid on firms as prominent change agents in a modern industrial network economy. Understanding the contemporary profound changes requires a thorough analysis of the life course - and critical change moments - of firms and organizations. Clearly, such studies are abundantly available in organizational sociology and industrial organization, but feature far less in regional science (van Wissen and van Dijk 2004). The present paper argues that an explicit spatial perspective, with a clear emphasis on statistical and modelling experiments, may offer new insights, from both a theoretical and a modelling perspective. We will discuss a number of theoretical approaches that contribute to this field, notably elements of evolutionary economics, organizational ecology, industrial organization, and entrepreneurship studies. We will then proceed by presenting a number of modelling strategies when dealing with spatial change 
from this perspective. These include approaches for modelling new firm formation, growth, and survival, as well as labour market approaches to entrepreneurship. A number of promising future developments is evaluated. Here, contributions from sociology, demography, computational economics and industrial organization, and regional science prove to be very promising. We conclude that firm demographics is a promising new research field.

\section{The Location of Firms}

Location theory of firms is at the heart of the analysis of the space-economy. Spatial decisions and industrial-economic decisions of firms are closely interconnected phenomena, be it that locational decisions are less frequent and represent often more an innovative act. The changing scene of entrepreneurial behaviour in our complex and often virtual network economy does not mean a significant change in the above-mentioned observations on spatial behaviour of firms.

Location theory is a traditional focal point in regional science. Both theoretically and empirically numerous contributions have been made in this framework in order to study the 'where' and the 'why there' of human activities, in regard to both firms and households. Here we will address in particular firm location.

Theoretically, in the past decades traditional location theory à la Weber and Lösch has been developed much further, by investigating spatial synergies (e.g., industrial complexes), spatial dynamics (e.g., innovation behaviour of firms, migration behaviour of households), and complex spatial systems (e.g., entropy and gravity models, (micro-)simulation analysis). Conventional economic cost concepts are increasingly broadened so as to include also image factors and information access in locational decisions. Following the well-known Tiebout hypothesis, also the locational analysis of public services has gained more importance (e.g., by referring explicitly to equity issues and multi-level policy structures).

The research instruments for analyzing locational patterns have also shown a profound extension. Notably in the field of discrete choice theory much progress has been made (e.g., by linking it to panel and longitudinal data), inter alia in the area of residential location analysis, migration analysis, transport behaviour, labour market research or location behaviour of firms. Especially the strong formal links between individual utility theory and macro-systems equilibrium have to be mentioned here, so that there is a formal correspondence between micro behaviour and macro functioning of a spatial system. More recently, also the dynamics of such behavioural-based spatial developments have been analyzed by new methodological advances (e.g., bifurcation theory, chaos and fractal theory, or at a micro level hazard modelling).

From a methodological viewpoint, much attention in the location literature has been devoted to the concept of a region as the home place of firms (e.g., homogeneous region, planning region etc.), while more recently many efforts have been made at developing a formal taxonomy and axiomatic typology of regions (e.g., by using fuzzy set analysis and abstract topology). Unfortunately, such contributions have remained fairly abstract thus far. But questions of spatial scale and concentration have remained an important point of analytical attention over the years. In dealing with these issues, regional science has always been marked by a strong quantitative and model orientation. Examples are amongst others: general spectral analysis, spatial autocorrelation analysis, spatial econometrics, input-output models, entropy models, catastrophe analysis, disaggregate choice analysis, spatial interaction models and non-linear spatial dynamics. Especially (multi-)regional input-output models have proven to be important operational methods in regional analysis, although unfortunately many regional authorities are somewhat hesitant in investing in the construction of regional input- 
output models. But the current problems of regional resource scarcity and environmental decay will hopefully generate a new interest in regional input-output studies complemented with pollution and resource sectors.

Finally, from a practical viewpoint an enormous variety of contributions to locational analysis can be found, focusing on the spatial choice behaviour of households and their commuting patterns or on the spatial re-orientation of firms as a result of high-tech developments.

In recent years, we have witnessed an increasing interest in innovative jumps in firm behaviour, which may have implications for their locational strategies. The introduction of virtual organizations, trans-border networks and ICT developments has prompted a reorientation of the spatial profile of business life.

\section{Firms in an Innovative Network Context}

Firms operate in an increasingly changing environment. It is increasingly recognized that nodal points in a network, notably cities, play a strategic role in the creation and diffusion of innovations. Not only does the 'urban milieu' offer favourable seedbed conditions for innovative behaviour (e.g., socio-cultural facilities, knowledge and education infrastructure, financial and venture capital support mechanisms, and institutional/managerial ramifications), but it also acts as a catalyst for transmitting new findings to other places in a network (through its connectivity infrastructure). Clearly, the adoption and diffusion of innovation may take a multiplicity of forms (e.g., satellite communication, teleport networks, physical transportation, logistics and telematics platforms etc.). Cities are essentially focal points of transactions favouring new ways of doing things. Such transformation processes clearly have a geographical and time dimension, as explained in traditional space-time geography.

The analysis of spatial, temporal and spatio-temporal diffusion already has a long history, not only in geography or marketing, but also in biology and medicine. Diffusion theory offers a multidisciplinary framework of analysis for a wide range of phenomena, e.g., migration, distribution of news, pollution, acceptance of innovations, spread of epidemic diseases, transportation and technology transfer. An extensive survey of different models can be found in the historical work by Rogers (1983) and more recently Banks (1993). In the course of time there has also been an analytical shift from simple exponential and logistic distribution functions to time-dependent growth parameters and critical threshold levels (see Nijkamp and Reggiani 1994).

The revival of Schumpeterian views on current economic restructuring phenomena has increasingly induced scientific interest in business innovations. Both the behavioural stimuli and the selection environment for the creation and adoption of technological and organizational change in firms have become a subject of intensive study (cf. Suarez-Villa and Fischer 1995). In this context a rich field of economic research has recently been developed, including, for instance, long wave tests, analysis of incubation hypotheses, impact studies on small and medium-sized enterprises, neo-Fordist approaches to industrial organization and labour markets, and the growth potential of high technology industries (cf. Suarez-Villa and Hasnath 1993). Several studies have been devoted to the seedbed conditions of new technologies, especially in the context of small and medium-size firms. Two particular lines of inquiry have called for much attention in the recent past, viz. the urban incubator hypothesis and the product life-cycle model. Both approaches focus on dynamic competition of firms.

The need for technological innovation starts normally in the competitive environment of the firm. New products and ideas are necessary in order to guarantee survival of the firm, 
leading to the intrinsic need for dynamic behaviour, risk management, ICT adoption and the like.

When an innovation is successful, companies have a competitive advantage for a certain period. Competition may emerge from various sources, and this focuses attention on the firm's environment, which we will now discuss.

In the context of competitive behaviour, Porter (1990) has emphasized five forces of competition. These five forces determine industrial profitability because they determine the prices firms can charge, the costs they have to bear, and the investment required to compete in the industry. The threat of new entrants limits the overall profit potential in the industry, because new entrants bring new capacity and seek a new market share, while pushing the margins down. Powerful buyers or suppliers bargain away their own profits. Fierce competitive rivalry erodes profits, since it brings higher costs (like e.g., for advertising, sales, or R\&D) or by passing on profits to customers in the form of lower prices. The presence of close substitute products limits the price competitors can charge without inducing substitution and eroding the industry's volume. Companies must defend themselves against competition, but use the opportunities offered by competition. In this context, Porter has formulated generic strategies to develop a situation of competitive advantage. These strategies are cost leadership and product differentiation. Both cost leadership and differentiation can be achieved by following the strategy advocated in Schumpeter's works.

Porter's five forces are clearly present in the economic environment of companies, especially regarding the market and the technology. Environment can also be understood here in a more narrow, spatial sense. According to the latter interpretation, the environment refers, for example, to infrastructure, transport possibilities, the labour market, the capital market, energy, raw materials and the local government.

The latter observation calls for more analytical attention to the impact of geographical locations on the process of technological change. In an urban context, the existence of forward and backward linkages between industrial and service sectors means that new innovations may have substantial multiplier effects on the whole urban economy, especially if these effects are of a cumulative and circular nature (the 'urban breeding place' hypothesis). In this way, innovations may also stimulate a recovery from urban decline processes. Therefore, cities may offer a diversity of valuable facilities, making it easier for companies to develop innovations.

Urban areas are agents or incubators of economic, social, scientific, technological and cultural change. They are sources of socio-economic mutation through their cultural opportunities and their geographical connectivity. As a result, cities have become complex entities, with a multidimensional portfolio of economic, social, political and cultural features, which offer a competitive advantage in terms of labour skills, locational possibilities, capital assets, infrastructural provisions, and socio-cultural amenities. Such a heterogeneous configuration creates the conditions for survival and continuity, even though urban developments may exhibit fluctuating growth patterns (see Nijkamp 1990). At the same time, cities are also early adopters of innovations generated elsewhere. Thus, modern cities seem to offer the most favourable selection environment for new ideas and new ways of doing things.

The spread of innovations does not take place in a random way, but follows organized structures based on interaction and communications networks. It is increasingly recognized that most modern companies operate in an uncertain dynamic environment. The world is more and more characterized by a complex web of relationships. Network relationships seem to become an important feature of industrial economies nowadays (Kamann and Strijker 1991). According to Damman (1994), there are two reasons for the emergence of this phenomenon: first, since the early 1980s, companies have increasingly withdrawn from non-core activities, 
leaving these activities to various suppliers. Second, related to this is the increased flexibility in production based on the decline of demand for mass products.

In our examination of the relevance of diffusion patterns, we will focus in particular on network use and knowledge in a modern industrial economic system. Uncertainty, and the related presence of imperfect information, prevents a pure price mechanism from allocating resources in an optimal way and driving economic activities to a stable competitive equilibrium. Uncertainty can only be incorporated in a competitive equilibrium system by assuming an equal (imperfect) access for all individuals to the same information (Ouwersloot 1994); a condition which, in the presence of highly differentiated firm sizes, market structures and spatial situations can be considered highly unrealistic. In their economic behaviour and decision-making processes, companies are usually facing different kinds of uncertainty.

While complexity will cause uncertainty, the local environment of a company may be considered one of the most important uncertainty-reducing factors. The local environment can be defined as a set of territorial relationships encompassing in a coherent way a production system, different economic and social actors, a specific culture and representation system, which generate a dynamic collective learning process. These circumstances offer an environment for a highly dynamic business climate for firms.

\section{Firm Dynamics in a Demographic Perspective}

Modern economic and technological systems are in a state of flux. Consequently, recent years have witnessed an avalanche of interest in entrepreneurship, in particular the critical success factors of the modern 'entrepreneurial hero' and the wider urban and regional development implications of emerging entrepreneurship in favourable seedbed areas. It goes without saying that in the recent past also the conditions that facilitate proper entrepreneurship policy or the opportunities of public-private partnership constellations have received increasing attention. Research in this field has focused in particular on fact finding, on theory development and on modelling contributions and has aimed to get a better understanding of this complex multiactor force field. Contributions have been made by representatives from different disciplines, in particular economics, regional science, industrial organization or behavioral psychology. And in this context, the critical importance of knowledge and information in our ICT driven world is increasingly recognized and it has become an important field of study, in particular from a micro perspective.

The shift from a macro- to a micro-perspective of regional economic growth has also resulted in a shift towards methods and models for analysing individual firm and entrepreneurial behaviour (van Wissen and van Dijk 2004). The modern field of the demography of firms embraces a collection of theoretical, analytical and empirical tools for the study of firm dynamics. It is a highly multi- and interdisciplinary field of research, and may serve as a framework for more analytical and empirical research focussed on the spacetime behaviour of firms and entrepreneurship (van Wissen 2002, Nijkamp 2003). In this section we will sketch some selected prominent themes in this new approach, with special emphasis on the available modelling tools.

The concept of demography, when applied to firms, is a metaphor, and therefore by definition not completely correct. Rather, it serves as a heuristic device to transfer some new concepts, ideas and models into the study of economic change. This application is by no means entirely new nor unique. In the history of regional science, studies on entry, startups, new entrepreneurship or firm migration have a respectable tradition, but in recent years the scope of the field has broadened to encompass all aspects of firm dynamics. The key concept in demography is time. Its meaning in demography is similar to the meaning of space in geography; moreover, time and space are interlinked phenomena. Demography studies the 
timing of events. Traditionally in human demography this was confined to the events of birth and death, but the life course between both events has become important too. In social science, time can be decomposed into three different dimensions: individual time (age), calendar or historical time (period), and social time (cohort), which is the interaction between personal and historical time. The cohort is a central concept in the study of social change (Ryder 1965). When dealing with a firm life course perspective, to be discussed below, another time dimension might be added: the product life cycle. This decomposition is a very useful device for the explanation and modelling of firm dynamics. The multidimensionality of time, therefore, includes different levels of analysis, and hence enables a link between the micro level of the individual, the meso level of the market, and the macro level of the (regional, space-time) economy.

Firm dynamics is studied by sociologists, economists, geographers and demographers, and although there are many differences in approach, they share a set of common themes (van Wissen 2002, Boone and van Witteloostuijn 1995). First, there is a common focus on change and dynamics, instead of on equilibrium and stability. Second, change is the result of selective entry and exit into and out of the population, and/or adaptive behaviour of incumbent firms in the stock. There are large differences as well. Industrial organization deals with entry, exit, and firm growth in markets, and the interaction between these events and market structure (see e.g., Brown and Duguid 2001, Elfring and Hulsink 2003 and Hitt et al. 2001). Evolutionary economics is also focused on change, but deals not so much with individual firms but with the inheritance of routines, which are the genetic material, the sets of rules, knowledge, procedures and expertise for production processes. Organizational sociologists (organizational ecologists) study the evolution of the number of firms in a population of organizations over time, in terms of founding and disbanding processes. In geography and regional science, traditionally the attention was mainly directed to regional variation in entry and exit, as well as to firm relocation processes, although the notion of a cohort of firms was introduced already earlier by Wever (1984). We will deal with the spatial dimension in firm demography in more detail in Section 7 . But first we will turn to modelling approaches in firm demography.

\section{Modelling Firm Demographic Events}

Modelling complex phenomena is a since qua non for developing testable propositions. In this overview we include modelling approaches both of business demography and of entrepreneurship analysis. The demography of entrepreneurs and of enterprises are distinct but interrelated phenomena. In a life course approach to the firm, which we will discuss below, both fit naturally under the umbrella of the demographic component of entry or firm founding. Each of the demographic events will be discussed below, and a distinction is made between new entrepreneurship and other foundings as different routes to new firm formation.

\section{New entrepreneurship}

There are at least two ways of looking at firm founding: one approach sees the decision to start a firm as an individual decision to become an entrepreneur. The other approach views firm founding as an organizational process. Audretsch and Fritsch (1994) label these two processes the labour market approach and the ecological approach. In the first approach, the number of new entrepreneurs in a given period is divided by the size of the labour force to arrive at the startup rate, while in the other one the number of new firms is divided by the total number of firms. Koster and van Wissen (2004), on the basis of several studies as well as their own analysis, estimate the share of firm based foundings (spin-offs) in the total number of 
firm foundings to fall between 10 to 40 percent. Individual startups, or new entrepreneurship are predominant in new firm formation.

There is an abundant supply of entrepreneurship studies, dealing with the issue of explaining the transition into entrepreneurship. Within the field of labour market economics, the transition into self-employment is the equivalent of this topic (Blanchflower 2000, Blanchflower and Oswald 1993). A micro and a macro approach can be distinguished in this context. At the micro level, surveys form the empirical basis for modelling the decision to become entrepreneur/self-employed. A recent example of a large international survey of new entrepreneurship is the Global Entrepreneurship Monitor GEM (Reynolds et al. 2002). In labour market analysis, the population is sub-divided into non-active and active population, and the active population is further sub-divided into employed and unemployed persons. Changes in these states in the labor market as well as the duration in these states are key variables to be analyzed and explained. The working population may be further classified into being employed and employer or entrepreneur, or being employed, self-employed and employer/entrepreneur. Changes into and out of the state of being not active, unemployed, employee, self-employed or employer can be studied using discrete choice models or event history models, the latter taking into account the sojourn times into the various states in the labour market, e.g. the duration of stay in unemployment. Modeling entrepreneurship using demographic tools is also appropriate. The population at risk and the event can be defined, and multistate labor market participation models can be extended to include entrepreneurship and self-employment. Nevertheless, this route to entrepreneurship projections has not been followed yet. Rather, the emphasis is on the factors explaining entrepreneurship. In the entrepreneurial literature, the factors affecting the transition into entrepreneurship from a micro perspective are (see e.g. Verheul et al. 2002):

- micro-economic factors: employment status, earning differentials, occupational history, liquidity constraints;

- cultural and psychological factors: risk and uncertainty aversion; span of control, selfesteem and self-satisfaction;

- socio-demographic factors: age, sex, ethnicity, education, family structure.

In macro studies of entrepreneurship mainly national or regional differences in entrepreneurial activity rate are modeled. Here, the dependent variable is either the percentage of the workforce in self-employment or the probability or rate of becoming selfemployed/entrepreneur in a given period. The latter indicator makes more sense from a methodological and theoretical point of view. Macro level factors are (see e.g. Blanchflower 2000, Blanchflower and Oswald 2000, Staber and Bogenholdt 1993):

- economic factors: the level of economic development of a country, the economic structure, the nature of technological change, industry life cycle, market concentration, unemployment levels

- institutional factors: taxation, minimum wage levels, pension rights, social security system, legislation, informal barriers to entry

- cultural factors (see e.g. Hofstede 1991): individualization index of society, uncertainty avoidance index, dissatisfaction index

- demographic factors: age/sex/ethnic composition of the workforce, population growth, population density 
Entry can also be viewed as an organizational process (see also Levitt and March 1988). Both in industrial organization and in organizational ecology the founding rate is defined as the number of new firms divided by the number of incumbent firms. However, this cannot be defined as the population at risk, since it is doubtful if each firm founding is the result of a decision taken by an incumbent firm. Clearly, for spin-offs, new branch openings and so on, the firm is involved in the founding decision, but this is not the case for new entrepreneurship (Koster and van Wissen 2004). Nevertheless, the resulting founding rate is commonly used in industrial organization and organizational ecology as the dependent variables. Nevertheless, entry, the key variable in industrial organization, has a different meaning than firm founding in organizational ecology: the first relates to the entry of new products in a market, the second to the entry of firms in a population. Despite this important distinction, there are many parallels between both approaches (Boone and van Witteloostuijn 1995), and this is caused by the basic fact that most firms serve only one market. A clear parallel is the relation between the product life cycle and entry in industrial organization (IO) and the density dependence model and firm founding in organizational ecology (OE): Entry/founding is high in the early stages of a new product, where product innovation dominates, and levels off in later phases of the product life cycle. First, the point of market saturation is reached (which is called carrying capacity), and a 'shake out' takes place afterwards, in which the entry/founding rate is very low, and exits are high. In the 'shake out' phase process innovation dominates, and only a few large firms survive. The density dependence model and its relation with entry and exit has been confirmed for many different industries in many different countries (Carroll and Hannan 2000). According to OE there are two main factors explaining this pattern of firm founding within the population life cycle: the first is legitimation ('taken-for-grantedness') of a product in society, which has a positive relation with the size of the population, as well as with founding, but up to a saturation level. The second is competition, which has a negative relationship with the population size and firm founding. The social concept of legitimation includes the creation of a social structure in the environment of the firm, and has a number of clear similarities with the notion of the entrepreneur as a 'networker' (van Wissen 2004). The concept of competition, although defined more broadly as competition for resources, comes close to the economic notion of competition. However, here IO has more to add. The most important factors explaining entry from a IO point of view are (see e.g. Siegfried and Evans 1994, Geroski 1995, Caves 1998):

- product market expansion: entry is higher in expanding markets, indicated by e.g. population and income growth;

- product life cycle: entry is high in the early phases of product innovation, and low in the 'shake-out' phase where process-innovation leads to economies of scale for a few large firms;

- market structure: entry is low in concentrated markets

- barriers to entry: legislation, cartels, etc.

Although these factors are clear from a theoretical economic view, empirical evidence for these relationships are not always easy to find (Geroski 1995, Siegfried and Evans 1994). In addition to these factors, some of the factors that are dominant in entrepreneurship studies are relevant as well here. Again, spatial factors play a minor role in the IO and OE literature.

In IO the process of spin-offs also receives attention (Klepper 2001, Agarwal et al. 2003). Here the attention is focused on knowledge transfer and success of off-spring. The mother-child relationship makes it fit for a demographic analysis as well. Such an analysis 
would for example reveal the relationship between age of the mother-firm and the spin-off rate, or the relationship between health of the mother and survival probability of the child.

Modelling firm founding in IO or OE is usually in the form of time series analysis of one market/population (and OE takes usually very long time periods, starting for instance with the invention of the car, or with the rise of the beer industry well back in the $17^{\text {th }}$ century in Bavaria), or cross-sectional analysis of different sectors and countries. This research scheme is also followed in economic geography (see e.g. Reynolds et al. 1994).

\section{Survival and firm closure}

Exit and closure have received much less attention in the literature in IO and in spatial sciences. Nevertheless, they are important too, because they separate the unsuccessful from the successful innovators, and also highly relevant in the selection mechanism governing industrial change from an evolutionary perspective (Nelson and Winter 1982). Although comparing international or interregional entry rates is often used to evaluate economic vitality and innovativeness, it might make more sense to study net entry rates, i.e. the net effect of entry and exits.

From a methodological point of view firm mortality is the most demographic component, since it can be tackled with standard life table techniques. Nevertheless, the process leading to death is largely different between biological agents and organizations. Whereas for biological entities mortality is a function of the underlying 'force of mortality', that increases as age progresses, for organizations other processes are at work. In the organizational literature, these forces are called 'liabilities':

- the liability of newness: failure risk is highest at the youngest ages (Stinchcombe 1965);

- the liability of adolescence: it is often found that failure risk is highest not at the very young ages, but after one or two years, when the starting captical has run out, and the intitial spirit has lost its momentum (Brüderl and Schussler 1990);

- the liability of smallness: small firms have a higher failure risk;

Thus, age is a key factor explaining inter-firm variation in survival rates. However, since age and firm size are highly correlated, there is some discussion about the independent effects of each of these factors (see Carroll and Hannan 2000).

In the OE literature, similar to the firm founding, in the density dependence model there is a strong link between population size and exit, which is mostly the result of interorganizational competition. The IO literature also recognizes the link between the product life cycle and exit rates, and adds a number of economic factors to these. These are mostly the mirror factors that explain entry, such as market contraction and barriers to exit. In addition, entry and exit rates are highly correlated. Three explanations are offered for this phenomenon (Johnson and Parker 1994):

- the "Marshall" effect: every founding will eventually result in an exit. Given that about 50 percent of entries fails within 5 years, exit rates must be high shortly after high entry rates, leading to a positive association;

- the Competition effect: an entry increases competition and therefore increases exit (a positive relationships);

- the Multiplier effect: new firms generate new business opportunities for other firms. Therefore entry and exit are negatively related. 
The empirical outcome of these associations varies between sectors, and there is also a spatial dimension involved (DeJardin 2004).

The firm mortality life table conveys a significant amount of information about survival risks over the life course of a firm. The form of the survival curve reveals for instance if the early years of the firm are the most vulnerable years, or if the structural long term level is relatively high compared to other regions or countries.

\section{Firm relocation}

Firm relocation is almost exclusively studied by economic geographers, although in game theory and operations research the legacy of Hotelling in optimal firm (re)location strategies is kept alive (see e.g. Eiselt et al. 1993). Different types of processes are collected under the heading of firm relocation: a complete move of a firm, a partial move of a unit of a firm, or even the opening up of a new branch of a firm in a new location. Systematic research about the differences between these processes is lacking. Similar to standing practice in human demography, the firm relocation decision process can be decomposed into the decision to move and the decision to choose another location, conditional on being a mover, and each of these two decisions may be decomposed further into smaller steps, such as the decision to want to move. Modelling tools for the decision to move are probabilistic choice models, or transition rate models. If timing of the decision is involved, event-history models are appropriate as well.

In the past, the firm external conditions, and in particular the locational characteristics were the dominant explanatory factor, but more recently firm internal factors, such as growth and reorganisation have become more important (van Dijk and Pellenbarg, 2001; Pellenbarg et al. 2003). The emphasis on firm internal factors makes this component more prone to demographic analysis. For instance, Brouwer et al. (2004) investigated the relocation decisions of larger firms ( $>200$ employees) using an international survey, and found out that employment change (both increases and decreases), as well as mergers, acquisitions, takeovers induce relocation behaviour. Moreover, the relocation propensity decreases with size and with age. This suggests a close link between the life course of the firm and relocation behaviour, with high relocation propensities at the stages of firm expansion at younger ages, and low relocation propensities in later, more stable circumstances. However, these linkages have not been investigated in depth yet. The application of model migration schedules might give additional information about structural patterns of timing and incidence of migration decisions over the life course, for different sectors and regions (Rogers and Castro 1981).

The literature about relocating firms' destination choice is vast, and overlaps significantly with location models, the only difference being that the firm has a history of having been located in another place first. We will not go into detail of location theory here, rather point at some stylised facts that are relevant for modelling relocation decisions. First, relocation of firms is usually over very small distances: there is a strong distance decay. Second, traditional locational characteristics as well as cost minimization principles are of limited importance in explaining site choice. Other -institutional- factors seem to play a more important role.

\section{Firm size change}

Although firm size change (usually measured in terms of the number of employees) does not fit in the standard set of demographic components, it is an element of firm demography. Firm size is an extremely important firm characteristic, and demographic events are strongly associated with changes in firm size. For instance, firm survival increases with increasing size, whereas firm relocation propensity decreases with firm size. This component has been 
studied mainly in the field of industrial organization (for an overview see Caves 1998), but has received little attention in geography, regional science or organizational ecology. In IO (where it is -confusingly- called firm mobility: see Caves 1998) most literature has focused around testing the Law of Proportionate Effect or Gibrat's Law, stating that the firm growth rate is independent of its size. Although there is no intrinsic reason why this law should hold (Gibrat was a mathematician, not an economist) it holds remarkably well in many empirical tests, and is often a good first approximation (Sutton 1997). In general it is found that small firms growth faster than large firms, and young firms faster than old, and that the growth rate variation around the mean decreases with increasing size (whereas Gibrat's Law implies that the variance is independent of size). The standard method to estimate this model is to use a time series model of a log transformed standardized growth rate with serially correlated errors (Chesher 1979). In recent research a more general approach is used in which various explanatory variables are used to explain size change over time, including firm size at time t-1 and serially correlated errors. For instance, significant differences have been found between economic sectors. Whereas it appears that in the manufacturing sector small firm grow faster, Audretsch et al. (2002) found that in service sectors in the Netherlands Gibrat's Law holds. Their main argument is that scale economies are not very important in the service sector. Again, not much attention has been devoted to the formal demographic aspects of firm size change, or to the spatial aspects of firm growth differentials. With respect to the demographic aspects, a negative relationship between age and growth has been confirmed in many studies, but it is conceivable that periods of growth and stagnation alternate in different phases of the firm life course, and that these cycles have some relationship with the economic business cycle as well as with the stage in the product life cycle.

\section{The Firm Life Course as a Framework for Firm Demographic Modelling}

In the previous section we have shown that most firm demographic events have an age dimension, and show systematic variation over time as well, since most events are related to macro-economic business cycles and may show other time dependent trends, as a result of e.g. policies, institutional change and so on. In addition, for a given product, the product life cycle is an important clock, which has many important consequences for the behaviour of the individual firm. The cohort is the interaction between these time dimensions and shows the mean development path of the life courses of the aggregate of firms that were founded in the same period. If there is little variation in these firm life courses age is an excellent indicator of this development path. However, firms, depending on the circumstances of the start, the goals of the founder(s), the economic business cycle, and many other factors, among which the spatial environment is not the least important, will follow different growth trajectories, leading to widely diverging growth paths. A firm life course approach is a useful framework for theory and analysis of these complex phenomena. The life course approach has gained popularity in social science and particular in sociology and demography in recent years. In a life course perspective life is viewed as an evolving process of demographic events around which subjects organize their lives in various interacting life domains (Van Wissen and Dykstra 1999). Life course analysis deals with the explanation of the timing and incidence of these events and with the question what this means at the population level (Willekens 1999). The life course framework can play a useful role in firm demography as well, since it is an extension of demographic tools applied in a more complex setting. This rests on the assumption that a firm is not only an economic, but also a social organization, that can be studied in a social setting as well.

In particular, the following elements of the life course framework are very useful in a firm demographic setting: 
- individual firm biographies are organized in number of domains. Each domain is characterized by a set of connected events and states. For instance a capital domain may be defined, dealing with acquiring capital, or a legal domain, which involves all events and states around the legal status of the firm. Other examples are the management domain, the ownership domain, the labour domain, the housing domain, the R\&D domain, the network domain, and so on. The company biography is composed of the ensemble of the development trajectories through all relevant domains;

- each of these trajectories may be studied independently, using panel or event-history models. Path-dependence, heterogeneity, state dependence and other dynamic effects may be important;

- these trajectories within the firm biography interact. Events and states in one trajectory may have an effect on other trajectories. For instance, the labour trajectory (firm growth) may have an effect on the legal trajectory, for instance when the size of the firm increases beyond a threshold level and the legal status changes from a partnership to a private limited company. Likewise the capital and labour trajectories will interact, etc.

- not only trajectories within one firm biography interact, there are also interactions between firms. These are of various nature: competitive as well as synergetic, such as vertical linkages of supply and delivery, but also learning networks and so on;

- firm biographies are nested in an environment that involves other firms, institutions, and a spatial environment. The specific trajectories in a biography are the result of firm choice behaviour within a constraining and enabling environment.

The life course framework is a heuristic device for the demographic study and analysis of complex behaviour of firms in time, both from a micro and a macro point of view. For example, the firm life course approach may give a unified view on the issue of the linkages between entrepreneurship and new firm formation. A firm start-up by an individual entrepreneur may be viewed as a specific instance of the crossing of the trajectories of management and ownership. A transition from one state to another within the management trajectory (for instance, when the entrepreneur withdraws from active management and hires a paid manager), or within the ownership trajectory (for instance, when the owner sells a large part of his company) marks a critical episode for the company and marks the shift of the firm from a entrepreneurial initiative to another firm type. There are many partial theories about specific segments of these trajectories and specific events. An example of a comprehensive theory encompassing the early growth stages of the firm is the resource based theory as depicted by Garnsey (2000).

\section{Space-Time Developments in Business Life}

Time and space and time and intimately related. In the previous sections we proposed a demographic life course framework for dealing with timing of entrepreneurial and firm activities. At the same time it is clear that different critical events and episodes in the life course of a firm or enterprise are closely related to spatial conditions and decisions as well. This implies that the firm life path has a corresponding spatial dimension, with structural features relating to the firm life course. A number of important notions and concepts have been mentioned already. When dealing with firm formation and new entrepreneurial activities, cities may function as breeding places, or incubation centres. Certain non-urban regions may similarly act as clusters of networks with the same breeding place function. 
Learning and networking are the most important mechanisms which make one place different from another, although the traditional agglomeration economies or the availability of the labour market, and specialised forward and backward linkages are of course still relevant as well. There is an increasing number of studies dealing with both individual level characteristics and regional variables for the explanation of new entrepreneurship (see e.g. Wagner and Sternberg 2004). These studies find that individual and regional level characteristics both have explanatory value for predicting new entrepreneurship. A disadvantage is that regional characteristics are treated as exogenous, whereas they may change as a result of the intensity of the dependent variable. For models of new entrepreneurial activities, these feedback effects between the characteristics of the regional economy and firm founding, which are typical of agglomeration and spatial cluster effects, imply that single equation models are not appropriate, at least not for dealing with explaining long term time trends. A feedback effect from the macro regional level to micro founding intensities is required. An example of such a feedback mechanism is given in van Wissen (2002), or in Carree and Thürik (1999). In both applications the ecological concept of the carrying capacity is used. The carrying capacity is endogenous and changes as a result of inand decreases in the size of (local) business populations and consumers, who exert a (local) demand for products. More general, existing models of firm founding in organizational ecology and industrial organization primarily look at intersectoral and intertemporal differences, but disregard to a large extent the spatial variation, although this addition would be possible without problems (van Wissen 2004).

Another important link between space and time in the development of business life is the product life cycle. Networking, and learning are more important in the early stages of the product life cycle (see also van Oort 2004). In the early stage of the product life cycle, innovations are important, and these tend to occur as a result of investments in human knowledge, not physical capital. In later product phases, investments are more and more in machines and equipments, which lowers the chances of new innovations by individuals. Moreover, in the shake-out period firms try to internalize knowlegde and other externalities as much as possible, and this implies that the locational requirements in each of the phases is different. Firms that started in cities and clusters may tend to relocate in later phases of the product life cycle, not only because of scale effects, but also because there are no advantages of being in close proximity of competitors.

Spatial and regional effects in firm growth have not been studied in depth yet, although in extended versions of tests of the Law of Proportionate Effects regional variables are taken into account as controls. In an explicit test for the Netherlands, Huisman and van Wissen found small although sometimes significant differences between firm growth in the Randstad and in other regions (Huisman and van Wissen 2003). However, this result is somewhat surprising, since the same regional factors that stimulate founding, i.e. localized learning and networking, should also be important for (early) growth of firms.

An important issue in space-time development of business life is the spatial development of regional clusters, especially in view of the increasing (international) mobility of firms. For instance, Italian industrial clusters increasingly experience relocation of resources to regions in Central-European countries (e.g. Slovenia or Romania, see Mariotti 2004). The question is here if this is a threat or opportunity for the long term survival of these clusters. This depends on the fate of individual firms in the cluster, and of the development of the cluster network. One option is, that a clusters develops in specific regions, with close ties with the parent network. This would lead to a structured diffusion process of the kind discussed by e.g. van Oort and Atzema (2004). 


\section{A Research Agenda}

The aim of the present paper was to review a number of recent entrepreneurial studies from a methodological perspective. A prominent role was given to the field of the demography of the firm, and more specifically the notion of the firm life course, which is the way firms organize their life path in sequences of critical events, decisions, and periods. It was also recognized that the dimension of time and space are highly connected in business life. Not only is firm mobility increasing, but entrepreneurs are increasingly networkers. The emergence of virtual and dynamic networks of entrepreneurs calls for new methods of research of dealing with these issues. Clearly, from a demographic point of view, there are some parallels with household formation and dissolution, and a whole array of methods exist for dealing with them. Nevertheless, these methods may be fruitful in analyzing changes in network structures, but are not very informative in dealing with the qualitative aspects of networking. Other methods should be developed here. These methods should also incorporate spatial clustering as a possible outcome of these processes.

An important role of the spatial environment for firms and networks is the provision of security and trust, not only in an individual setting but also from the perspective of institutional embeddedness and non-formal public-private governance. The economics of trust, as developed for instance by Casson (1995), forms an important future field of work on entrepreneurship in a space-time framework.

Finally, the life course of the firm is not yet a well developed concept. Important concepts are: what are the crucial domains of interest; how do these domains interact; what is the influence of virtual enterprises on firm location and market behaviour; which lessons can be derived from the modern geography of innovation; how do flexible specialisation and emerging industrial networks impact on business strategies; and what is the role of space involved in each of these domains and events and episodes therein? Moreover, the constraining and enabling role of the spatial environment, and other actors in the spatial network, should be defined and studied in more detail. It goes without saying that firm demographics offers a new inspiring domain for creative regional science research, as this approach is able to act as an interface between individual industrial decisions and spatial development patterns. 


\section{References}

Acs Z (2002) Innovation and the Growth of Cities, Edward Elgar, Cheltenham, UK

Agarwal R, R Echambi, AM. Franco and MB Sarkar (2003) Inheritance by the unintended child: the impact of knowledge transfer on spin-out generation, development and performance. Champaign

Audretsch DB, L Klomp, E Santarelli and AR Thurik (2002) Gibrat's Law: Are the Services Different? EIM Research Report H200201 SCALES: Zoetermeer

Audretsch D and M Fritsch (1994) On the measurement of entry rates. Empirica 21: 105-113

Banks RB (1993) Growth and Diffusion Phenomena, Springer Verlag, Berlin

Blanchflower DG. (2000) Self-employment in OECD countries. Labour Economics 7: 471505

Blanchflower DG. and AJ Oswald (1998) What makes an entrepreneur? Journal of Labour Economics 16(1): 26-60

Boekema FK, MS Bakkers and R Rutten (eds.) (2000) Knowledge, Innovation and Economic Growth, Edward Elgar, Cheltenham

Boone, C and A van Witteloostuijn (1995) Industrial organization and organizational ecology: the potentials for cross-fertilization. Organizational Studies 16: 265-298

Brouwer AE, I Mariotti and JN van Ommeren (2004) The firm relocation decision: an empirical investigation Annals of Regional Science

Brown JS, and P Duguid (2001) Knowledge and Organization. Organization Science 14: 319340

Brüderl J and R Schussler (1990) Organizational mortality: the liability of newness and adolescence. Administrative Science Quarterly 35: 530-537

Carree MA and AR Thürik (1999) The carrying capacity and entry and exit flows in retailing. International Journal of Industrial Organization 17: 985-1007

Carroll, GR and MT Hannan (2000) The Demography of Corporations and Industries. Princeton University Press, Princeton NJ

Casson M (1995) Studies in the Economics of Trust. Aldershot: Elgar

Caves RE (1998) Industrial organization and new findings on the turnover and mobility of firms. Journal of Economic Literature 36: 1947-1982

Chesher AD (1979) Testing the law of proportionate effect The Journal of Industrial Economics, Volume 27(4) :403-411

Damman M (1994) Individual and Spatial Success Factors in Innovative Firms. Master's Thesis, Dept. of Economics and Business Administration, Free University, Amsterdam

Dejardin M (2004) Sectoral and Cross-Sectoral Effects of Retailing Firm Demographies. Annals of Regional Science (forthcoming)

Dykstra PA and LJG van Wissen (1999) Introduction: The life course approach as an interdisciplinary framework for population studies. In: Van Wissen LJG and PA Dykstra (eds.) Population Issues: An Interdisciplinary Focus. Kluwer Academic/Plenum Publishers : New York

Eiselt HA, G Laporte and JF Thisse (1993) Competitive location models: a framework and bibliography. In: Transportation Science 27: 44-54

Elfring, T. and C. Hulsingk (2003), Networks in Entrepreneurship, Small Business Economics 21: $409-422$

Garnsey E. (1998). A theory of the early growth of the firm. Industrial and Corporate Change 7 (3) p. 523-556

Geroski P (1995) What do we know about entry? International Journal of Industrial Organization 13(4): 421-440 
Hitt MA, RD Ireland, SM Camp, and DL Sexton (2001), Strategic Entrepreneurship, Strategic Management Journal 22: 479-491

Huisman C and L van Wissen (2003) Firm growth across regions: a regional test of Gibat's law: paper ERSA conference, Jyväskylä, August 27-30, 2003

Hofstede G (1991) Cultures and Organizations: Software of the Mind. McGraw-Hill, London Johnson P and S Parker (1994) The interrelationships between births and deaths. Small Business Economics 6:283-290

Kamann DJ and D Strijker(1991) The Network Approach: Concepts and Application, in: R. Camagni (ed.) Innovation Networks: Spatial Perspectives Belhaven Press

Klepper SJ (2001) Employee startups in high-tech industries. Industrial and Corporate Change 10: 639-674

Koster S and LJG van Wissen (2004) Inherited resources and company support as basis for new firm formation.A taxonomy of founding types: start-ups, spin-outs, and spin-offs. Paper $6^{\text {th }}$ Uddevalla symposium on Entrepreneurship, spatial industrial clusters and inter-firm networks, June 12-14, 2003

Levitt B and JG March (1988) Organizational Learning, Annual Review of Sociology 14: 319340

Marsili O (2001) The Anatomy and Evolution of Industries, Edward Elgar, Cheltenham, UK

Nelson RR. and S Winter (1982) An Evolutionary Theory of Economic Change Cambridge University Press, Cambridge MA

Nijkamp P (2003) Entrepreneurship in a Modern Network Economy. Regional Studies 37(4): 395-405

Nijkamp P (ed.) (1990) Sustainability of Urban Systems, Gower, Aldershot, UK

Nijkamp P and A Reggiani (eds.) (1994) Non-lineear Evolution of Spatial Economic Systems, Springer Verlag, Berlin

Norton RD (2001) Creating the New Economy, Edward Elgar, Cheltenham, UK

Oakey R (ed.)(1996) New Technology-Based Firms in the 1990s, Chapman, London

Ouwersloot H (1994) Information and Communication from an Economic Perspective, $\mathrm{PhD}$ Thesis, Free University, Amsterdam

Pellenbarg PH, LJG van Wissen and J van Dijk (2002) Firm Migration, in: Ph. McCann (ed) Industrial Location Economics Cheltenham: Edward Elgar 110-148

Peneder M (2001) Entrepreneurial Competition and Industrial Location, Edward Elgar, Cheltenham

Porter ME (1990) The Competitive Advantage of Nations, Free Press, New York

Reynolds PD et al. (2002) GEM Global Entrepreneurship Monitor. 2002 Executive Report. Ewing Marion Kauffman Foundation, Kansas City.Staber, U. \& D. Bogenholdt (1993) Self-employment: a study of seventeen OECD countries. In: Industrial Relations Journal 24: 126-137

Reynolds PD, DJ Storey and P Westhead (1994) Cross-national comparisons of the variation in new firm formation rates. Regional Studies 28: 443-456

Rogers A and LJ Castro (1981) Model migration schedules. IIASA research Report RR 81-30, Laxenburg: Austria

Rogers EM (1983) Diffusion of Innovations, Free Press, New York

Ryder N (1965) The cohort as a concept in the study of social change. American Sociological Review 30: 843-861

Siegfried JJ and LB Evans (1994) Empirical studies of entry and exit: a survey of the evidence. Review of of Industrial Organization 9: 121-155

Stinchcombe AL (1965) Social structure and organizations. J March (ed.) Handbook of Organizations, Rand McNally, Chicago: 142-193

Suarez-Villa L (1989) The Evolution of Regional Economies, Praeger, New York 
Suarez-Villa L and MM Fischer (1995) Technology, organization and export-driven research and development in Austria's electronics industry, Regional Studies, 29(1): 19-42

Suarez-Villa L and SA Hasnath (1993) The effect of infrastructure on invention Technological Forecasting and Social Change 44(3): 333-358

Sutton J (1997) Gibrat's legacy Journal of Economic Literature 35(1): 40-59

Van Dijk J and PH Pellenbarg (2000) The firm relocation decision Papers in Regional Science 79(2): 191-220

Van Oort FG (2004) Urban Growth and Innovation, Ashgate, Aldershot, UK

Van Oort FG and OALC Atzema (2004) On the conceptualization of agglomeration economies: the case of new firm formation in the Dutch ICT sector Annals of Regional Science 38 (forthcoming)

Van Wissen LJG (2000), A Micro-simulation model of firms: Applications of concepts of the demography of firms', Papers in Regional Science 79 (1): 111-134

Van Wissen LJG (2002) Demography of the Firm: a useful metaphor? European Journal of Population, 18(3): 263-279

Van Wissen, L.J.G. 2002, 'Demography of the Firm. A Useful Metaphor?', European Journal of Population 18(3), 263-279

Van Wissen LJG (2004) A spatial interpretation of the density dependence model in industrial demography. Towards a synthesis with spatial sciences. Small Business Economics 16 (forthcoming)

Van Wissen LJG and J van Dijk (2004) Introduction to Special Issue: Demography of the Firm and Spatial Dynamics. Annals of Regional Science 38 (forthcoming)

Verheul I, WS Wennekers D Audretsch and R Thurik (2002) An eclectic theory of entrepreneurship: Policies, institutions and culture. In Audretsch D et al. (eds.) Entrepreneurship: Determinants and policy in a European-U.S. Comparison. Kluwer, Boston, Dordrecht, London 11-82

Wagner J and R Sternberg (2004) Start-up activities, individual characteristics, and the regional milieu: Lessons for entrepreneurship support policies from German micro data Annals of Regional Science 38 (forthcoming)

Wever E (1983) Cohort analysis in economic geography Tijdschrift Economische en Sociale Geografie TESG 74: 217-223

Willekens FJ (1999) The life course: models and analysis. In: Van Wissen LJG and PA Dykstra (eds.) Population Issues: An Interdisciplinary Focus. Kluwer Academic/Plenum Publishers : New York 